\title{
MYCOBACTERIA PRODUCE PROTEINS INVOLVED IN BIOFILM FORMATION AND GROWTH-AFFECTING PROCESSES
}

\author{
JOANA KORABLIOVIENE $\dot{1}^{1,2 *}$, MYKOLAS MAURICAS ${ }^{1}$,

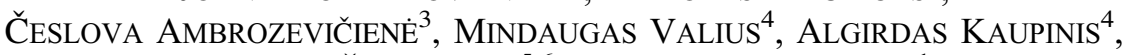 \\ SAULIUS ČAPLINSKAS ${ }^{5,6}$ and PAVEL KORABLIOV ${ }^{1}$ \\ ${ }^{1}$ Department of Immunology, State Research Institute, Centre for \\ Innovative Medicine, Vilnius, Lithuania \\ ${ }^{2}$ Department of Epidemiological Surveillance, Centre for Communicable Diseases and \\ AIDS, Vilnius, Lithuania \\ ${ }^{3}$ Department of Bacteriology, National Food and Veterinary Risk \\ Assessment Institute, Vilnius, Lithuania \\ ${ }^{4}$ Vilnius University Life Sciences Center, Institute of Biochemistry, \\ Proteomics Center, Vilnius, Lithuania \\ ${ }^{5}$ Faculty of Social Policy, Mykolo Romerio University, Vilnius, Lithuania \\ ${ }^{6}$ Centre for Communicable Diseases and AIDS, Vilnius, Lithuania
}

(Received: 17 July 2017; accepted: 31 May 2018)

The aim of this study was to determine the effect of mycobacterial proteins on mycobacterial biofilm formation and growth processes. We separated growthaffecting proteins (GEPs) from wild type of Mycobacterium bovis and ATCC strain of Mycobacterium avium subsp. avium. Our results showed that these mycobacteriasecreted GEPs are involved in biofilm formation, growth stimulatory, and inhibitory processes. Our findings suggest that GEP stimulated M. avium subsp. avium growth in vitro. Stimulation process was observed in mycobacteria affected with GEP extracted from M. avium subsp. avium. We found that both GEPs inhibited the growth of the $M$. bovis. Optical density measurement and visual analysis confirm that GEP plays an important role in biofilm formation process. Most of M. bovis GEP are associated with the type VII secretion and general secretion pathways. Our results contribute to a better understanding of the mechanisms underlying mycobacterial biofilm formation and growth-affecting processes and better characterization of mycobacterial proteins and their functions. It is noteworthy that this finding represents the first demonstration of GEP-mediated growth effects on a solid and liquid medium.

Keywords: mycobacterial proteins, mycobacterial biofilms, mycobacterial growth processes

*Corresponding author; E-mail: tamkeviciute.joana@gmail.com 


\section{Introduction}

The ability of bacteria to communicate and behave as a group for social interactions like a multicellular organism has provided significant benefits to bacteria in host colonization, formation of biofilms, defense against competitors, and adaptation to changing environments [1]. Many bacteria have been found to regulate diverse physiological processes and group activities through a mechanism called quorum sensing (QS) [2].

With the emergence of drug resistance, treating mycobacterial infections is becoming increasingly difficult and hence, looking for newer drug targets, especially those involving QS, is an essential component of mycobacterial research. However, the Gram-positive mycobacteria remain a mystery with no clear evidence known about their QS mechanism [3]. Bioinformatics analysis has revealed the presence of LuxR homologs in Mycobacterium tuberculosis, but the experimental supports are lacking $[4,5]$. Some of these homologs are ubiquitous across the multiple mycobacterial species and are involved in mycobacterial biofilm formation or persistence, suggesting a possible existence of similar QS mechanisms. Given the fact that biofilm formation is mostly linked with QS regulation [3], the existence of QS in mycobacteria cannot be ruled out. However, this hypothesis needs experimental validation [6].

M. tuberculosis typically forms pellicles at the liquid-air interface in growth media. In recent times, pellicles have been equated to biofilms, because they are held together by extracellular polymeric substance (EPS) produced by the bacterium [7]. M. tuberculosis forms biofilms harboring antibiotic-tolerant bacilli in vitro, but the factors that induce biofilm formation and the nature of the extracellular material (ECM) that holds the cells together are poorly understood, polysaccharides, proteins, DNA, and lipids are important components of the ECM $[8,9]$. However, the composition of the mycobacteria biofilm EPS and the mechanisms governing its formation remain poorly understood [9]. It is known that proteinaceous components include cell surface adhesins, protein subunits of flagella, and pili, secreted extracellular proteins, and proteins of outer membrane vesicles [10]. Better characterization of the proteinaceous components structure, functions, and regulatory circuits controlling biofilm matrix production will provide better understanding of mycobacteria physiological processes, such as host colonization, defense against competitors, and adaptation to changing environments (e.g., antibiotic resistance). Understanding these mechanisms and their controlled social activities may open a new avenue for controlling mycobacterial infections $[1,6,10]$. In this study, we determine the effect of mycobacterial proteins on mycobacteria biofilm formation and growth processes. We characterize these proteins by their gene name, status of existence, molecular 
weight, location, function, superfamily, and secretion pathway. Biggest part of these proteins were associated with the type VII secretion (T7S) pathway.

\section{Materials and Methods}

\section{Bacterial strains and GEP preparation}

Wild type of Mycobacterium bovis and ATCC strains of Mycobacterium avium subsp. avium (ATCC 15769) and Mycobacterium terrae (ATCC 15755) were used throughout these studies. GEPs were extracted from M. bovis and M. avium subsp. avium and tested in vitro: MA GEP - GEP extracted from M. avium subsp. avium; MB GEP - GEP extracted from M. bovis. Cultures were centrifuged (at $4{ }^{\circ} \mathrm{C}$ for $45 \mathrm{~min}$ at $4,000 \mathrm{rcf}$ ) after 8 and 16 weeks of incubation and passed the filtrate through a low protein-binding 0.2- $\mu \mathrm{m}$ filter (Dismic-13 CP cellulose acetate filters, Advantec, Tokyo, Japan). Concentration of proteins (CP) was quantified by Bradford assay.

\section{Growth of bacteria}

Bacterial cultures $\left(10^{5} \mathrm{CFU} / \mathrm{ml}\right)$ were transferred on Lowenstein-Jensen medium with pyruvic acid (Becton, Dickinson and Company, http://www.bd.com/ europe/regulatory/Assets/IFU/Difco_BBL/244420.pdf). Cultures were affected by Blank Paper Disks (6 mm diameter, Becton, Dickinson and Company) impregnated with GEP and incubated at $37^{\circ} \mathrm{C}$ for 8 weeks. At the end of incubation, the number of bacteria colonies was calculated. In total, 100 samples were prepared.

\section{Biofilm formation}

To evaluate the effect of GEP on biofilm formation, bacterial cultures were raised in $15-\mathrm{ml}$ screw-capped bottles with $2 \mathrm{ml}$ of culture, $5 \mathrm{ml}$ of media, and $0.5 \mathrm{ml}$ of GEP. At the end of third week of incubation, the caps of bottles were loosened to allow further growth of Mycobacterium at the interface. Cultures were incubated at $37^{\circ} \mathrm{C}$ for 6 weeks.

\section{Congo red assay and cellulose optical density (OD) measurement}

About $2 \%$ of Congo red was added to both the control and test samples and continued shaking at $37^{\circ} \mathrm{C}$ for $2 \mathrm{~h}$. After $2 \mathrm{~h}$, control and mycobacterium biofilm 
cells were centrifuged at 5,000 $\mathrm{g}$ for $5 \mathrm{~min}$, washed three times with PBS, and then were analyzed visually for Congo red binding. OD measurement was performed at $500 \mathrm{~nm}$.

Filter-aided protein sample preparation (FASP)

Proteins were concentrated on Amicon Ultra- $0.5 \mathrm{~mL} 30 \mathrm{kDa}$ centrifugal filter. Trypsin digestion was performed according to a modified FASP protocol as described by Wisniewski et al. [11]. Briefly, proteins were washed with buffer containing $8 \mathrm{M}$ urea. The proteins were alkylated using iodoacetamide. Buffer was exchanged by washing twice with $50 \mathrm{mM} \mathrm{NH}_{4} \mathrm{HCO}_{3}$, and proteins were digested overnight with TPCK Trypsin 20233 (Thermo Scientific, USA). Then, peptides were recovered by centrifugation and washed with $20 \% \mathrm{CH}_{3} \mathrm{CN}$. Afterward, samples were lyophilized, redissolved in $0.1 \%$ formic acid, and analyzed by mass spectrometry (MS).

\section{Liquid chromatography (LC) and MS}

The liquid chromatography (LC) separation of trypsin-cleaved peptides was performed with nanoAcquity UPLC system (Waters Corporation, UK). Peptides were loaded on a reversed-phase trap column PST C18 (Waters Corporation) at a flow rate of $15 \mathrm{ml} / \mathrm{min}$ using loading buffer of $0.1 \%$ formic acid and subsequently separated on HSS-T3 $250 \mathrm{~mm}$ analytical column (Waters Corporation) in 30-min linear gradient (A: $0.1 \%$ formic acid, $\mathrm{B}: 100 \% \mathrm{CH}_{3} \mathrm{CN}$ and $0.1 \%$ formic acid at a flow rate of $300 \mathrm{nl} / \mathrm{min}$ ). The nano-LC was coupled online through HDMS Synapt G2 mass spectrometer (Waters Corporation). The data was acquired using Masslynx version 4.1 software (Waters Corporation) in a positive ion mode. LC-MS data were collected using data-independent acquisition mode MSE with online ion mobility separation. Mass range was set to $50-2,000 \mathrm{Da}$ with a scan time set to $0.75 \mathrm{~s}$. A reference compound [Glu1]-Fibrinopeptide B (Waters Corporation) was continuously infused $(500 \mathrm{fmol} / \mathrm{ml}$ at a flow rate $500 \mathrm{nl} / \mathrm{min})$ and scanned every $30 \mathrm{~s}$ for online mass spectrometer calibration purpose.

\section{Data processing, searching, and analysis}

Raw data files were processed and searched using ProteinLynx Global SERVER (PLGS) version 3.0.1 (Waters Corporation). Mycobacterium protein sequence database from uniprot (September 29, 2017) was used. The following parameters were used to generate peak lists: (1) minimum intensity for precursors 
was set to 135 counts, (2) minimum intensity for fragment ions was set to 25 counts, and (3) intensity was set to 750 counts. Processed data were analyzed using trypsin as the cleavage protease, one missed cleavage was allowed, fixed modification was set to carbamidomethylation of cysteines, and variable modification was set to oxidation of methionine. Minimum identification criteria included one fragment ions per peptide, three fragment ions per protein and minimum of two peptides per protein. The false discovery rate (FDR) for peptide and protein identification was determined based on the search of a reversed database, which was automatically generated using PLGS when global FDR was set to $4 \%$.

\section{Statistical analysis}

Statistically significant differences between the groups were examined by the Mann-Whitney $U$ test and Wilcoxon test; $p<0.05$ was considered statistically significant, $p<0.09$ - clear trend.

\section{Results}

\section{GEP role in bacterial growth}

We found that both GEPs inhibited the growth of M. bovis in vitro (Figure 1). The strongest inhibitory process was observed in M. bovis affected with MB GEP $(p=0.030)$. Our results indicated that MA GEP stimulated the growth of the $M$. avium subsp. avium, whereas MB GEP inhibited the process (Figure 1). Both GEPs stimulated the growth of the $M$. terrae. The strongest stimulation process was observed in M. terrae affected with MA GEP (Figure 1). Statistical significance of results is given in Table I.

\section{GEP role in bacterial biofilm formation}

Cellulose is a critical component of mycobacteria biofilms [9], we scraped the biofilm biomaterial and stained biofilms cellulose with Congo red. We observed that higher OD was in samples affected by GEP. OD measurement and visual analysis confirm that GEP plays an important role in biofilm formation process. In samples affected by GEP was enhanced bacterial pellicles, clumps, and aggregates formation process. The most striking OD and visual changes were in the $M$. bovis samples affected by MA GEP (Figure 2). We found that $M$. bovis and M. avium subsp. avium affected by GEP have tendency $(p=0.083)$ for higher OD. 


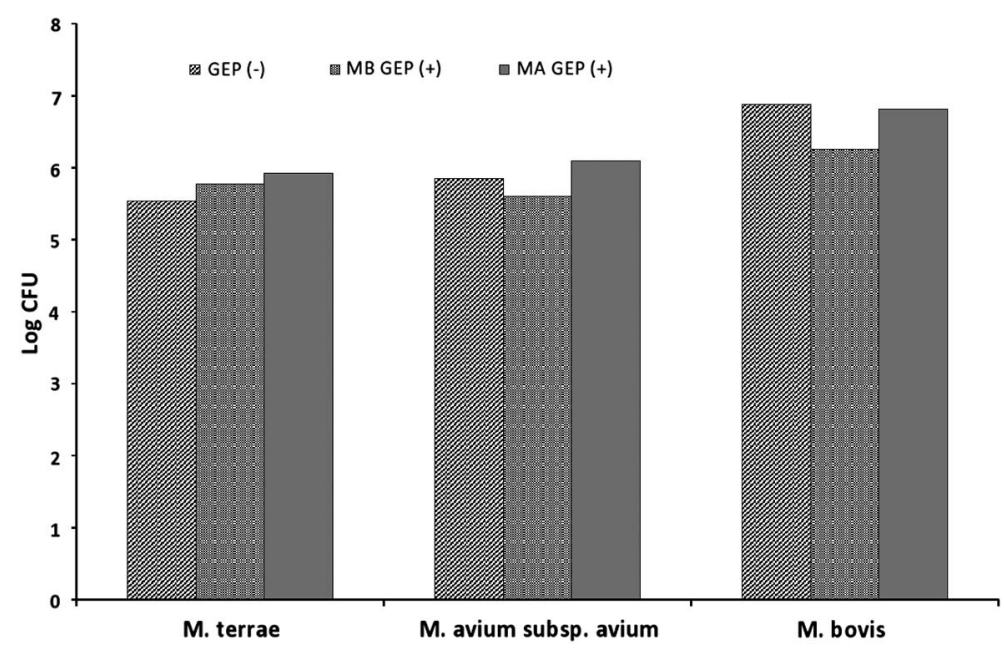

Figure 1. Effect of MB GEP (+) and MA GEP (+) on Log CFU of M. terrae, M. avium subsp. avium, and M.bovis. Mycobacterial samples without GEP (-) were considered to be control. GEP: growth-affecting protein; MA GEP: GEP extracted from $M$. avium subsp. avium; MB GEP: GEP extracted from $M$. bovis

Table I. Statistical significance of MB GEP and MA GEP on CFU/ml of mycobacteria

\begin{tabular}{lccccrr}
\hline Mycobacteria & GEP & Mean rank & Mann-Whitney $U$ & Wilcoxon $W$ & $z$ & $p$ \\
\hline M. avium & - & 10.25 & 2.500 & 57.500 & -1.623 & 0.121 \\
subsp. avium & MB GEP & 5.75 & & & & \\
& - & 3.75 & 4.500 & 7.500 & -1.186 & 0.273 \\
& MA GEP & 7.05 & & & & \\
M. bovis & - & 11.5 & 0.000 & 55.000 & -2.152 & 0.030 \\
& MB GEP & 5.5 & & & & \\
& - & 8.0 & 7.000 & 62.000 & -0.646 & 0.606 \\
& MA GEP & 6.2 & & & & \\
\hline
\end{tabular}

Note: Mycobacterial samples without GEP (-) were considered to be control. GEP: growth-affecting protein; MA GEP: GEP extracted from M. avium subsp. avium; MB GEP: GEP extracted from M. bovis.

Statistical significance of results is given in Table II. We did not find any statistically significance or tendency in samples with $M$. terrae.

\section{GEP identification}

We analyze GEP samples using FASP method and found 22 proteins. We found 20 proteins in MB GEP and two uncharacterized proteins in MA GEP samples (Table III). In samples from M.terrae, we did not find any proteins that were identifiable in uniprot database. 


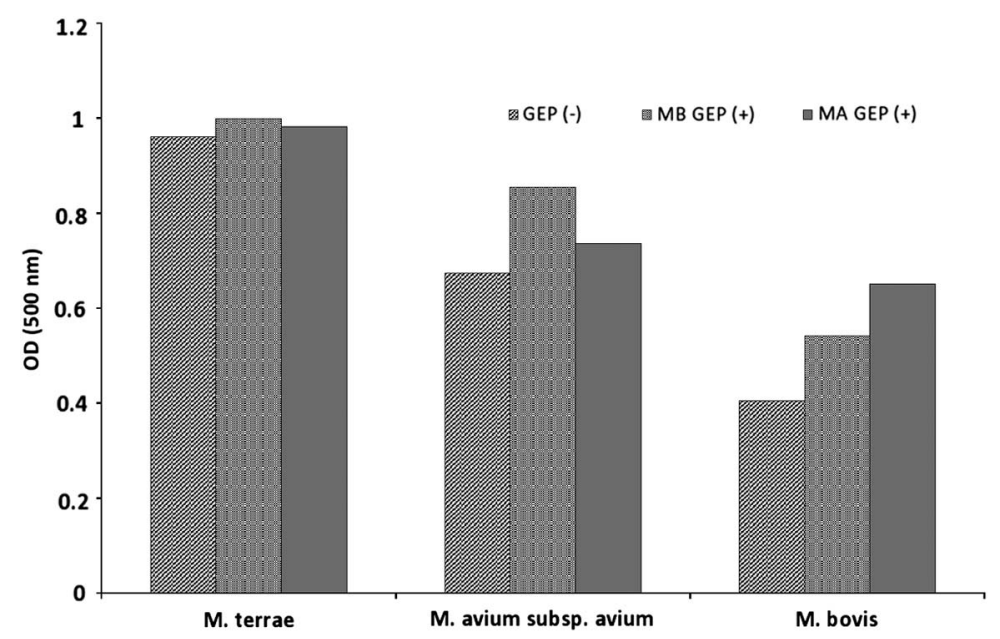

Figure 2. Effect of MB GEP (+) and MA GEP (+) on biofilms scraped from M. terrae, M. avium subsp. avium, and M. bovis was evaluated by cellulose optical density (OD) measurement. Mycobacterial samples without GEP (-) were considered to be control. GEP: growth-affecting protein; MA GEP: GEP extracted from M. avium subsp. avium; MB GEP: GEP extracted from M. bovis

Table II. Statistical significance of MB GEP and MA GEP on optical density of cellulose

\begin{tabular}{lccccrr}
\hline Mycobacteria & GEP & Mean rank & Mann-Whitney $U$ & Wilcoxon $W$ & $z$ & $p$ \\
\hline M. bovis & - & 1.50 & 0.000 & 3.000 & -1.732 & 0.083 \\
& MA GEP & 4.00 & & & & \\
& - & 1.50 & 0.000 & 3.000 & -1.732 & 0.083 \\
& MB GEP & 4.00 & & & & \\
M. avium & - & 1.50 & 0.000 & 3.000 & -1.732 & 0.083 \\
subsp. avium & MB GEP & 4.00 & & & & \\
& - & 1.50 & 0.000 & & & \\
& MA GEP & 4.00 & & & & \\
\hline
\end{tabular}

Note: Mycobacterial samples without GEP (-) were considered to be control. GEP: growth-affecting protein; MA GEP: GEP extracted from M. avium subsp. avium; MB GEP: GEP extracted from M. bovis.

\section{Discussion}

T7S and general secretion pathways associated with mycobacteria biofilm formation and growth processes

As mentioned above in samples affected by GEP were enhanced bacterial pellicles, clumps, and aggregates formation. The most striking OD and visual changes were in the $M$. bovis samples. We found that $M$. bovis and M. avium subsp. avium affected by GEP has tendency for higher OD. 


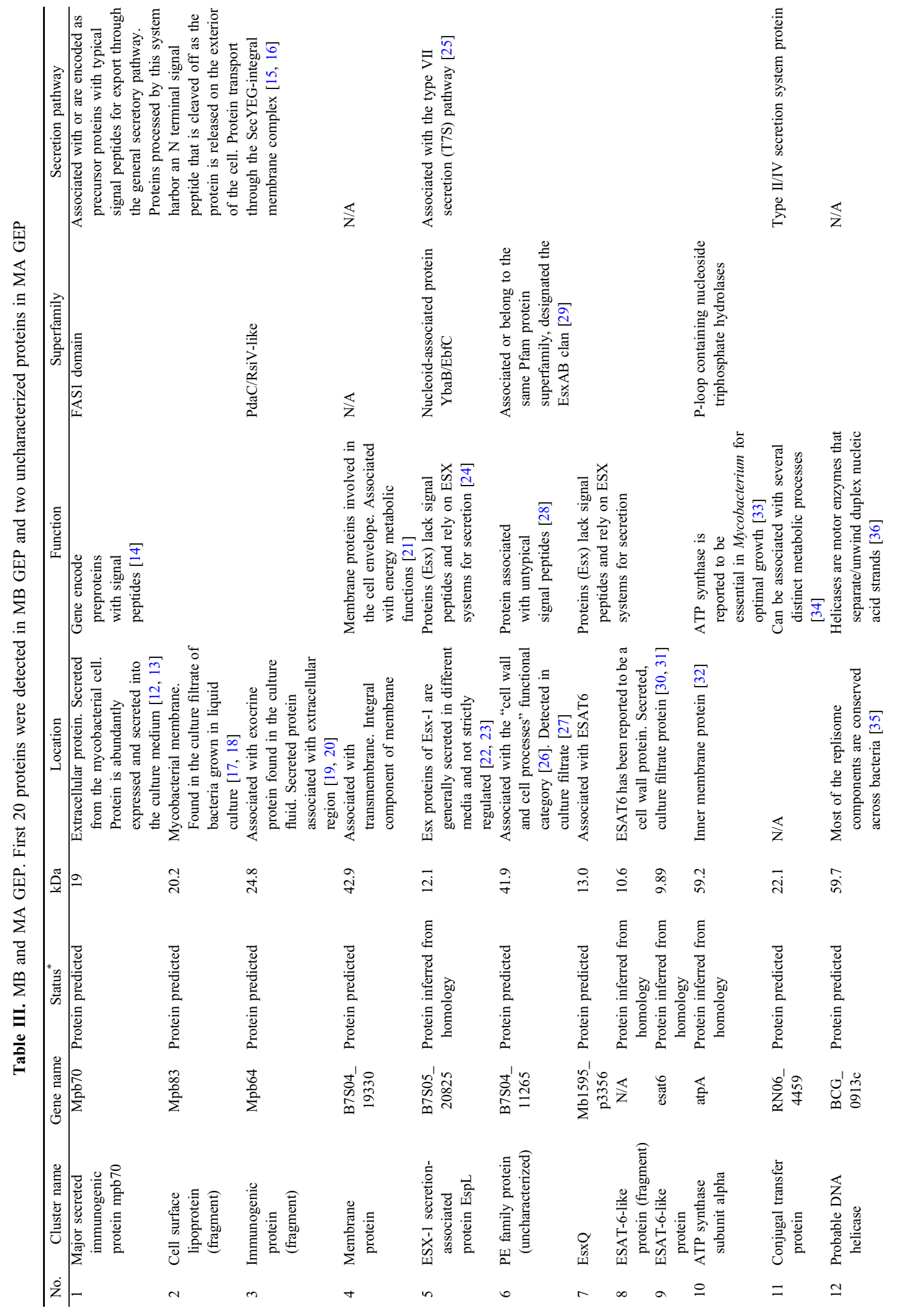




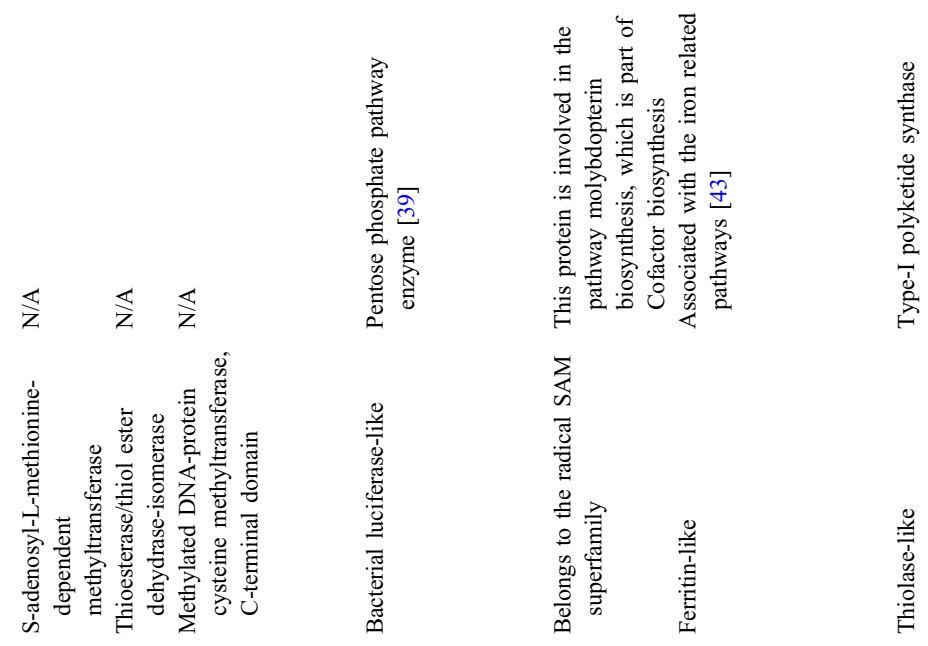

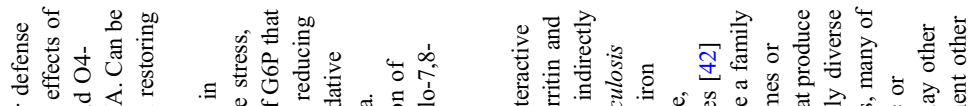

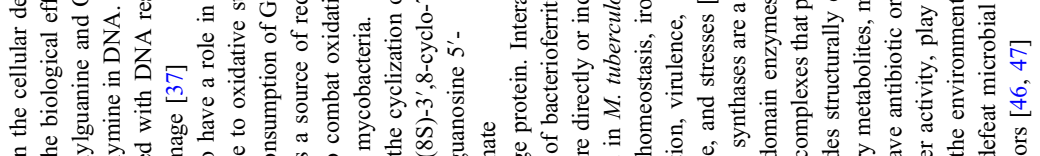

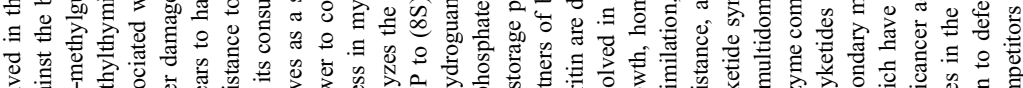

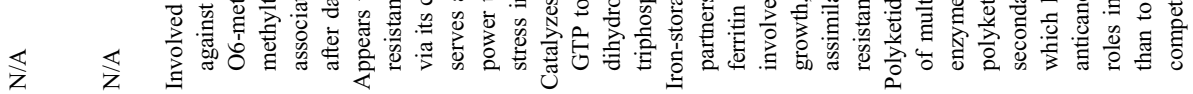

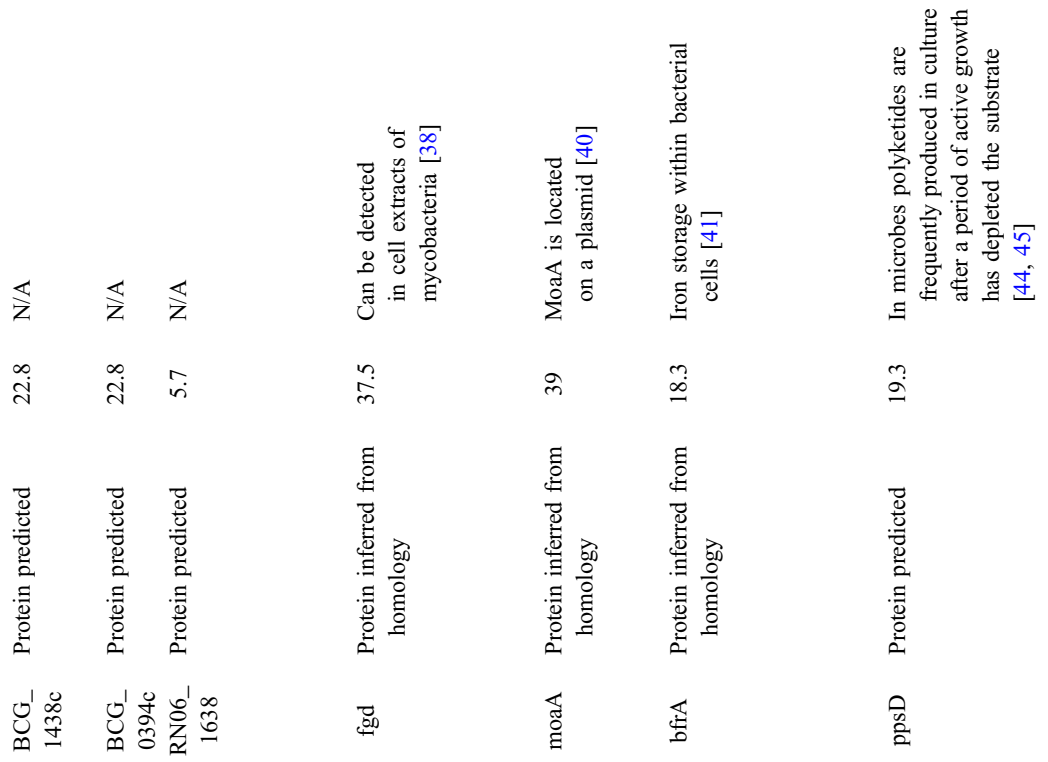

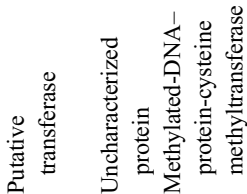

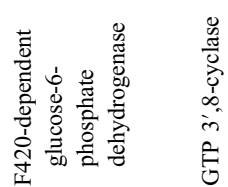
青

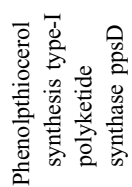

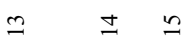
$\underline{-1}$
$=\stackrel{\infty}{=}$

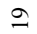




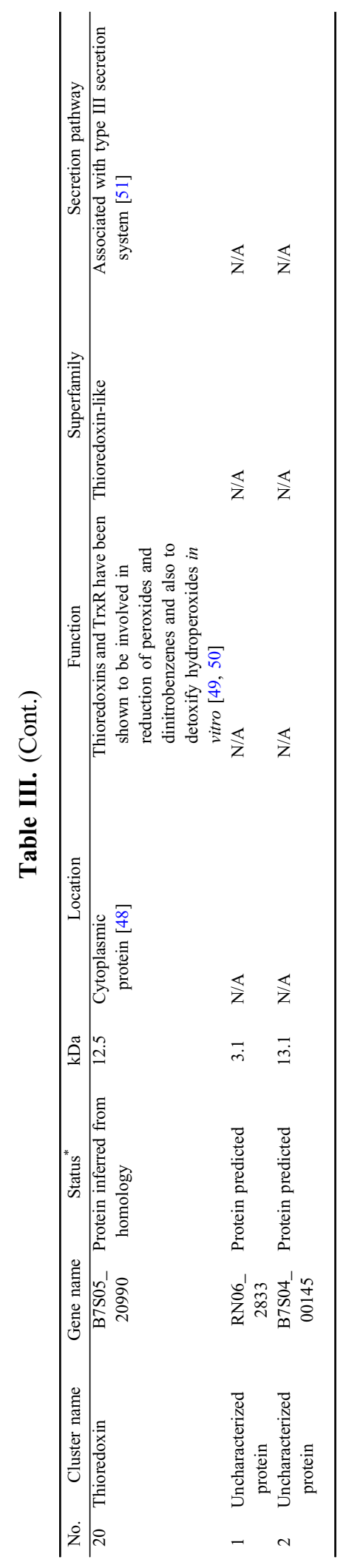


Proteinaceous components of the biofilm matrix included secreted extracellular proteins [10]. It is known that Mpb70, Mpb83, Mpb64, EspL, PE family and EsxQ, ESAT-6-like proteins, and ppsD are secreted into the culture medium and can be detectable in culture filtrate. Mpb70, Mpb83, Mpb64, EspL, PE family and EsxQ, and ESAT-6-like proteins are associated with signal peptides. All these proteins are associated with T7S and general secretion pathways (Table III).

Our results indicate that all GEPs inhibited the growth of the M. bovis. MB GEP inhibited the growth of the M. avium subsp. avium. The strongest inhibitory process was observed in M. bovis affected with MB GEP. As discussed above, mycobacteria differently react to their own and closely related slow-growing organism-secreted proteins. The results suggest that MB GEP inhibited M. bovis growth, while M. avium subsp. avium was stimulated by their own secreted GEP.

There is a lack of information about how mycobacteria responds to their own and closely related, slow-growing organism-secreted proteinaceous compounds. We identified GEP substrate and found that most of the GEP proteins associated with the T7S pathway. Our findings suggest that these mycobacteria-secreted GEP are involved in biofilm formation and growth-affecting processes.

The addition of GEP to liquid culture medium should aid the resumption of normal bacteria growth, which could potentially improve the diagnosis and quantification of mycobacterial infections. They may be involved in mycobacterial reactivation. As well as, these proteins can act as inhibitors. Our results contribute to a better understanding of the mechanisms underlying mycobacterial biofilm formation and growth-affecting processes and better characterization of mycobacterial proteins and their functions.

\section{Acknowledgements}

The authors are grateful to Mrs. Rita Viliene for her technical assistance.

\section{Conflict of Interest}

The authors declare no conflict of interest.

\section{References}

1. Li, Y. H., Tian, X.: Quorum sensing and bacterial social interactions in biofilms. Sensors 12, 2519-2538 (2012).

2. Waters, C. M., Bassler, B. L.: Quorum sensing: Cell-to-cell communication in bacteria. Annu Rev Cell Dev Biol 21, 319-346 (2005). 
3. Sharma, I. M., Petchiappan, A., Chatterji, D.: Quorum sensing and biofilm formation in mycobacteria: Role of C-di-GMP and methods to study this second messenger. IUBMB Life 66, 823-834 (2014).

4. Chen, J., Xie, J.: Role and regulation of bacterial LuxR-like regulators. J Cell Biochem 112, 2694-2702 (2011).

5. Santos, C. L., Correia-Neves, M., Moradas-Ferreira, P. A., Mendes, M. V.: A walk into the LuxR regulators of actinobacteria: Phylogenomic distribution and functional diversity. PLoS One 7, 46758 (2012).

6. Polkade, A. V., Mantri, S. S., Patwekar, U. J., Jangid, K.: Quorum sensing: An underexplored phenomenon in the phylum Actinobacteria. Front Microbiol 7, 131 (2016).

7. Ojha, A. K., Baughn, A. D., Sambandan, D., Hsu, T., Trivelli, X., Guerardel, Y., Alahari, A., Kremer, L., Jacobs, W. R., Jr., Hatfull, G. F.: Growth of Mycobacterium tuberculosis biofilms containing free mycolic acids and harbouring drug-tolerant bacteria. Mol Microbiol 69, 164-174 (2008).

8. Hans-Curt, F., Wingender, J.: The biofilm matrix. Nat Rev Microbiol 8, 623-633 (2010).

9. Trivedi, A., Mavi, P. S., Bhatt, D., Kumar, A.: Thiol reductive stress induces celluloseanchored biofilm formation in Mycobacterium tuberculosis. Nat Commun 7, 11392 (2016).

10. Fong, J. N. C., Yildiz, F. H.: Biofilm matrix proteins. Microbiol Spectr 3, 10 (2015).

11. Wisniewski, J. R., Zougman, A., Nagaraj, N., Mann M.: Universal sample preparation method for proteome analysis. Nat Methods 6, 359-362 (2009).

12. Lounatmaa, K., Brander, E.: Immunoelectron microscopic localization of $22 \mathrm{kDa}$ protein antigen in the surface layer of Mycobacterium bovis BCG strains. In Lounatmaa, K., Brander, E. (eds): Proceedings of the XIIth International Congress for Electron Microscopy. San Francisco Press Inc., San Francisco, 1990, pp. 894-895.

13. Abou-Zeid, C., Harboe, M., Rook, G. A.: Characterization of the secreted antigens of Mycobacterium bovis BCG: Comparison of the 46-kilodalton dimeric protein with proteins MPB64 and MPB70. Infect Immun 55, 3213-3214 (1987).

14. Wiker, H. G., Harboe, M., Nagai, S.: A localization index for distinction between extracellular and intracellular antigens of Mycobacterium tuberculosis. J Gen Microbiol 137, 875-884 (1991).

15. Wiker, H. G.: MPB70 and MPB83 - Major antigens of Mycobacterium bovis. Scand J Immunol 69, 492-499 (2009).

16. Jungnickel, B., Rapoport, T., Hartmann, E.: Protein translocation: Common themes from bacteria to man. FEBS Lett 6, 73-77 (1994).

17. Malen, H., Berven, F. S., Softeland, T., Arntzenn, M. O., D'santos, C. S., De Souza, G. A., Wiker, H. G.: Membrane and membrane-associated proteins in Triton X-114 extracts of Mycobacterium bovis BCG identified using a combination of gel-based and gel-free fractionation strategies. Proteomics 8, 1859-1870 (2008).

18. Harboe, M., Wiker, H. G., Ulvund, G., Lund-Pedersen, B., Andersen, A. B., Hewinson, R. G., Nagai, S.: MPB70 and MPB83 as indicators of protein localization in mycobacterial cells. Infect Immun 66, 289-296 (1998).

19. Harboe, M., Nagai, S., Patarroyo, M. E., Torres, M. L., Ramirez, C., Cruz, N.: Properties of proteins MPB64, MPB70, and MPB80 of Mycobacterium bovis BCG. Infect Immun 52, 293-302 (1986). 
20. Yamaguchi, R., Matsuo, K., Yamazaki, A., Abe, C., Nagai, S., Terasaka, K., Yamada, T.: Cloning and characterization of the gene for immunogenic protein MPB64 of Mycobacterium bovis BCG. Infect Immun 57, 283-288 (1989).

21. Gu, S., Chen, J., Dobos, K. M., Bradbury, E. M., Belisle, J. T., Chen, X.: Comprehensive proteomic profiling of the membrane constituents of a Mycobacterium tuberculosis strain. Mol Cell Proteom 2, 1284-1296 (2003).

22. Raman, S., Puyang, X., Cheng, T. Y., Young, D. C., Moody, D. B., Husson, R. N.: Mycobacterium tuberculosis SigM positively regulates Esx secreted protein and nonribosomal peptide synthetase genes and down regulates virulence-associated surface lipid synthesis. J Bacteriol 24, 8460-8468 (2006).

23. Agarwal, N., Woolwine, S. C., Tyagi, S., Bishai, W. R.: Characterization of the Mycobacterium tuberculosis sigma factor SigM by assessment of virulence and identification of SigM-dependent genes. Infect Immun 1, 452-461 (2007).

24. Abdallah, A. M., Gey van Pittius, N. C., Champion, P. A., Cox, J., Luirink, J., Vandenbroucke-Grauls, C. M., Appelmelk, B. J., Bitter, W.: Type VII secretion Mycobacteria show the way. Nat Rev Microbiol 5, 883-891 (2007).

25. Houben, N. G., Korotkov, K. V., Bitter, W.: Take five - Type VII secretion systems of mycobacteria. Biochim Biophys Acta 8, 1707-1716 (2014).

26. Mazandu, G. K., Mulder, N. J.: Function prediction and analysis of Mycobacterium tuberculosis hypothetical proteins. Int J Mol Sci 13, 7283-7302 (2012).

27. Fishbein, S., van Wyk, N., Warren, R. M., Sampson, S. L.: Phylogeny to function: PE/PPE protein evolution and impact on Mycobacterium tuberculosis pathogenicity. Mol Microbiol 5, 901-916 (2015).

28. de Souza, G. A., Leversen, N. A., Malen, H., Wiker, H. G.: Bacterial proteins with cleaved or uncleaved signal peptides of the general secretory pathway. J Proteomics 2, 502-510 (2011).

29. Chen, J. M., Zhang, M., Rybniker, J., Basterra, L., Dhar, N., Tischler, A. D., Pojer, F., Cole, S. T.: Phenotypic profiling of Mycobacterium tuberculosis EspA point-mutants reveals blockage of ESAT- 6 and CFP-10 secretion in vitro does not always correlate with attenuation of virulence. J Bacteriol 24, 5421-5430 (2013).

30. Majlessi, L., Brodin, P., Brosch, R., Rojas, M. J., Khun, H., Huerre, M., Cole, S. T., Leclerc, C.: Influence of ESAT-6 secretion system 1 (RD1) of Mycobacterium tuberculosis on the interaction between mycobacteria and the host immune system. J Immunol 174, 3570-3579 (2005).

31. Stanley, S. A., Raghavan, S., Hwang, W. W., Cox, J. S.: Acute infection and macrophage subversion by Mycobacterium tuberculosis require a specialized secretion system. Proc Natl Acad Sci U S A 22, 13001-13006 (2003).

32. Lai, E. M., Nair, U., Phadke, N. D., Maddock, J. R.: Proteomic screening and identification of differentially distributed membrane proteins in Escherichia coli. Mol Microbiol 52, 1029-1044 (2004).

33. Sassetti, C. M., Boyd, D. H., Rubin, E. J.: Genes required for mycobacterial growth defined by high density mutagenesis. Mol Microbiol 48, 77-84 (2003).

34. Lagrost, L., Desrumaux, C., Masson, D., Deckert, V., Gambert, P.: Structure and function of the plasma phospholipid transfer protein. Curr Opin Lipidol 9, 203-209 (1998).

35. Robinson, A., Causer, R. J., Dixon, N. E.: Architecture and conservation of the bacterial DNA replication machinery, an underexploited drug target. Curr Drug Targets 13, 352-372 (2012). 
36. Matson, S. W., Kaiser-Rogers, K. A.: DNA helicases. Annu Rev Biochem 59, 289-330 (1990).

37. Tuteja, N., Singh, M. B., Misra, M. K., Bhalla, P. L., Tuteja, R.: Molecular mechanisms of DNA damage and repair: Progress in plants. Crit Rev Biochem Mol Biol 36, 337-397 (2001).

38. Purwantini, E., Daniels, L.: Purification of a novel coenzyme F420-dependent glucose6-phosphate dehydrogenase from Mycobacterium smegmatis. J Bacteriol 10, 2861-2866 (1996).

39. Hasan, M. R., Rahman, M., Jaques, S., Purwantini, E., Daniels, L.: Glucose 6-phosphate accumulation in Mycobacteria: Implications for a novel F420-dependent anti-oxidant defense system. J Biol Chem 25, 19135-19144 (2010).

40. Solomon, P. S., Shaw, A. L., Lane, I., Hanson, G. R., Palmer, T., McEwanl, A. G.: Characterization of a molybdenum cofactor biosynthetic gene cluster in Rhodobacter capsulatus which is specific for the biogenesis of dimethylsulfoxide reductase. Microbiology 142, 1421-1429 (1999).

41. Masse, E., Gottesman, S.: A small RNA regulates the expression of genes involved in iron metabolism in Escherichia coli. Proc Natl Acad Sci U S A 99, 4620-4625 (2002).

42. Sharma, D., Bisht, D.: Role of bacterioferritin \& ferritin in M. tuberculosis pathogenesis and drug resistance: A future perspective by interactomic approach. Front Cell Infect Microbiol 7, 1-5 (2017).

43. Hameed, S., Pal, R., Fatima, Z.: Iron acquisition mechanisms: Promising target against Mycobacterium tuberculosis. Open Microbiol J 9, 91-97 (2015).

44. Bennett, J. W.: From molecular genetics and secondary metabolism to molecular metabolites and secondary genetics. Can J Botany 73, 917-924 (1995).

45. Bode, H. B., Bethe, B., Höfs, R., Zeeck, A.: Big effects from small changes: Possible ways to explore nature's chemical diversity. Chembiochem 3, 619-627 (2002).

46. Staunton, J., Weissman, K. J.: Polyketide biosynthesis: A millennium review. Nat Prod Rep 18, 380-416 (2001).

47. Adusumilli, S., Mve-Obiang, A., Sparer, T., Meyers, W., Hayman, J., Small, P. L.: Mycobacterium ulcerans toxic macrolide, mycolactone modulates the host immune response and cellular location of M. ulcerans in vitro and in vivo. Cell Microbiol 7, 1295-1304 (2005).

48. Aslund, F., Beckwith, J.: The thioredoxin superfamily: Redundancy, specificity, and grayarea genomics. J Bacteriol 181, 1375-1379 (1999).

49. Zhang, Z., Hillas, P. J., Ortiz de Montellano, P. R.: Reduction of peroxides and dinitrobenzenes by Mycobacterium tuberculosis thioredoxin and thioredoxin reductase. Arch Biochem Biophys 363, 19-26 (1999).

50. Jaeger, T., Budde, H., Flohe, L., Menge, U., Singh, M., Trujillo, M., Radi, R.: Multiple thioredoxin-mediated routes to detoxify hydroperoxides in Mycobacterium tuberculosis. Arch Biochem Biophys 423, 182-191 (2004).

51. Negrea, A., Bjur, E., Puiac, S., Ygberg, S. E., Åslund, F., Rhen, M.: Thioredoxin 1 participates in the activity of the Salmonella enterica serovar typhimurium pathogenicity island 2 Type III secretion system. J Bacteriol 191, 6918-6927 (2009). 